\title{
ETNIAS DE FRONTEIRA E QUESTÃO NACIONAL: O CASO DOS “REGRESSADOS” EM
}

\section{ANGOLA}

Luena Nascimento Nunes Pereira*

resumo: Este artigo trata dos ex-exilados angolanos, de origem etnolinguístico Bakongo, retornados a Luanda após um longo período de vivência no país vizinho Zaire (atual RDC), durante a guerra de independência de Angola ocorrida entre os anos de 1961-1974. Os Bakongo são uma "etnia de fronteira" presente tanto em Angola como nos dois Congos. O retorno deste grupo, com pelo menos uma geração nascida no exterior, sugere questões sobre a formação e o acirramento de identidades étnicas e o aparecimento de novas concepçóes de nacionalidade a partir de uma cultura construída numa experiência externa ao país. A busca de novas formas de participação de reconhecimento social e político através da disputa da legitimidade em torno de concepções de identidade nacional é mais um ingrediente complexificador no processo da reconstrução nacional de Angola.

palavras-chave: identidade nacional, etnicidade, Angola, bakongo abstract: This article deals with the Angolan former-exiled, ones of ethnolinguistic origin Bakongo, returning to Luanda, after a long period of experience in the neighboring country Zaire (current RDC), during the Angola's independence war, between the years of 19611974. The Bakongo is an "ethnic boundary" living in Angola as in the two Congos. The regress of this group, with at least one generation born in the exterior, suggests questions on the formation and the instigation of ethnic identities and the appearance of new conceptions of nationality from a culture constructed in a external experience to the country. The searching of new forms of participation of social recognition and politician through the dispute of the legitimacy around conceptions of national identity is an ingredient in the complex process of the national reconstruction of Angola.

key-words: national identity, ethnicity, Angola, bakongo

\section{INTRODUÇĀO}

A constituição dos Estados em África, organizada de acordo com o princípio de não alteração dos limites coloniais, ocasionou a manutenção de fronteiras que

Mestre em Antropologia Social pela USP e doutoranda do PPGAS/USP. Bolsista FAPESP. passaram por áreas ocupadas por grupos étnicos, grupos estes que não possuíam necessariamente limites territoriais precisos, prerrogativa essencial dos Estados-nações. A discussão sobre a relação entre etnias e Estados-nações em África foi sempre permeada pelo senso comum de que a instabilidade africana seria, a princípio, devida à formação de Estados multiétnicos, 
corpos políticos que abrigariam em seu seio uma miríade de povos culturalmente distintos e naturalmente hostis entre si. As etnias cortadas por fronteiras seriam mais um fator agravante de instabilidade política e social dos países emergentes.

Outros analistas, que descartaram acertadamente este tipo de explicação, centrado num essencialismo étnico, buscaram outras hipóteses - históricas e econômicas - para a crise africana, tais como o legado colonial, a adoção de governos autoritários, o não desenvolvimento social e econômico, a não inclusão de forças minoritárias no sistema político. É necessário, contudo, não perder de vista a dinâmica social e política mobilizada por grupos que transitam e se comunicam continuamente entre fronteiras nacionais.

Como exemplo para esta discussão, parto da pesquisa sobre ex-exilados angolanos de origem etnolingüística Bakongo retornados à capital do país depois da independência, após um longo período de vivência no país vizinho, Zaire (atual República Democrática do Congo), durante a guerra de libertação de Angola, ocorrida entre os anos de 1961 e 1974. Os Bakongo são o que chamo aqui de "etnia de fronteira", presentes tanto em Angola como nos dois Congos.

$\mathrm{O}$ retorno desse grupo, que inclui pelo menos uma geração nascida no exílio, sugere questôes sobre a formação e o acirramento de identidades étnicas e o aparecimento de novas concepçóes de nacionalidade a partir de uma cultura construída numa experiência externa ao país, estranha aos habitantes mais antigos da capital angolana.

A busca de novas formas de participação, de reconhecimento social e político, através da disputa da legitimidade em torno de concepções de identidade nacional é mais um ingrediente complexificador no processo da reconstrução nacional de Angola, ainda hoje mergulhada em conflitos civis.

\section{Angola}

Localizado na região austral da África, na costa ocidental, e com uma superfície de $1.246 \mathrm{~km}^{2}$, ou cinco vezes o tamanho do Estado de São Paulo, Angola é o 70 maior país da África em extensão. Sua população, estimada em 11 milhões de habitantes ${ }^{1}$, encontra-se desigualmente distribuída pelo território, já que $90 \%$ desta concentra-se na metade oeste do território e em torno de $50 \%$ nas cidades, principalmente na capital, Luanda, que deve ter atualmente cerca de 4 milhôes de habitantes.

A classificação das etnias em Angola historicamente tem levado em conta o tradicional critério lingüístico. Dessa forma, o país conta com cerca de dez grupos étnicos, sendo que os três maiores grupos Ovimbundu, Ambundo e Bakongo somam $75 \%$ da população².

De colonização portuguesa, Angola alcançou sua independência em 11 de novembro de 1975 , após catorze anos de guerra anti-colonial, encerrada em 1974 com a Revolução dos Cravos, que pôs fim, em Portugal, a cinqüenta anos de regime autoritário. De fins de 1974 a novembro de 1975 teve lugar o governo de transição, do qual participaram o novo governo português e os três movimentos de libertação até

1 As estimativas, feitas por diversas fontes, basearam-se no censo de 1991.

2 Esta população é, quase na sua totalidade, do tronco bantu, que predomina na região centro-sul da África. Outros pequenos grupos não-bantu em Angola são os Khun, vulgarmente chamados de bosquímanes, presentes no sul do país 
então reconhecidos ${ }^{3}$ : o MPLA Movimento Popular para Libertação de Angola; a FNLA - Frente Nacional de Libertação de Angola e a UNITA - União Nacional para a Independência Total de Angola.

A solução violenta para a libertação do jugo colonial foi comum em países que sofreram uma colonização com povoamento branco e/ou administração direta, caso das cinco colônias portuguesas em África ${ }^{4}$, cuja metrópole recusava-se a uma solução negociada, como aconteceu na grande maioria dos países africanos. Mas a peculiaridade de Angola está no fato de que, por diversos motivos, a luta armada foi levada a cabo por três movimentos de libertação, isolados e sem coordenação conjunta, que lutaram contra o poder colonial e, muitas vezes, entre si mesmos 5 .

No período do governo de transição, sediado em Luanda, em 1974, ficou clara a

Os três movimento tinham reconhecimento do novo governo português, da ONU e da OUA (Organização da Unidade Africana).

4 São elas Angola, Moçambique, Guiné Bissau, Cabo Verde e São Tomé e Príncipe. Ainda assim, a colonização portuguesa nestas cinco colônias foi bastante diferenciada, com maior presença de colonos em Angola e Moçambique do que na Guiné Bissau, por exemplo.

5 Embora seja uma tarefa muito perigosa, é possível identificar regiões de influência de cada um dos três movimentos: a FNLA teve predominância no norte, com o apoio majoritário da população bakongo; a UNITA atuou sobretudo na região do Planalto Central, de população ovimbundo, e o MPLA teve maior adesão na área centro-norte, de população ambundo, e nas cidades, principalmente na capital e região e em Benguela, mais ao sul do país. As áreas de influência são apenas um indicativo, sendo errôneo afirmar que houve um alinhamento meramente étnico a cada um dos movimentos de libertação. Fatores ideológicos, de urbanização e do processo de formação das elites dirigentes de cada um dos movimentos também influenciaram na formação das zonas de influência. O período da guerra anticolonial alterou significativamente estes alinhamentos iniciais. impossibilidade de os três movimentos formarem um só governo da nova Angola independente. Iniciou-se então uma guerra civil entre os movimentos, com participação de diferentes forças militares estrangeiras apoiando os diversos lados. Esta guerra foi vencida pelo MPLA, que assumiu sozinho o poder em novembro de 1975. Logo nos primeiros anos do governo do MPLA, que procurou implementar um regime de caráter socialista, teve início a guerra contra a UNITA.

Fenômeno tipicamente inscrito no contexto da Guerra Fria, no qual os países periféricos buscaram apoio dos dois blocos mundiais hegemônicos e, com isso, refletiram as rivalidades econômicas, políticas e ideológicas destes blocos, o conflito de Angola teve uma dimensão claramente internacionalizada. $\mathrm{O}$ regime do MPLA, liderado por Agostinho Neto, contou com o apoio (militar, logístico, técnico e/ou econômico) de Cuba, União Soviética e países do Leste Europeu. A UNITA, liderada por Jonas Savimbi, teve o apoio dos Estados Unidos e do regime racista da África do Sul.

$\mathrm{Na}$ dimensão regional, envolveram-se no conflito o antigo Zaire, que anteriormente apoiava a FNLA e depois passou a dar suporte à UNITA, e a Namíbia, cujo território, fronteiriço com Angola, era ocupado pela África do Sul. A organização que lutava pela emancipação namibiana - a SWAPO, que assumiu o poder em 1990, com a independência do país - era aliada do MPLA.

Os Acordos de Bicesse, em 1991, puseram fim à guerra e eleições para a presidência e para o parlamento foram marcadas para novembro de 1992. Todavia, a UNITA não aceitou a vitória do MPLA, num pleito legitimado pela ONU, e retornou ao conflito armado, dessa vez ainda 
mais aprofundado. Atualmente, assistimos à continuação dessa terceira guerra civil, recomeçada após o fracasso dos Acordos de Lusaka (1994) e do Governo de Unidade e Reconciliação Nacional (GURN).

\section{LUANDA E NORTE DE ANGOLA - DIFERENÇAS HISTORICAS E REGIONAIS}

O interesse no grupo de ex-exilados retornados do Zaire deve-se ao fato de este grupo ter tido uma longa vivência e socialização no país vizinho: mais de uma geração nasceu e cresceu no antigo Congo Belga (depois Zaire, atualmente República Democrática do Congo). O retorno dos exilados não é feito, na sua maioria, para a região de origem do grupo, o norte de Angola ${ }^{6}$, e sim para a capital do país, Luanda.

A região de Luanda possui uma especificidade dentro da história da colonização portuguesa em Angola. Não se trata apenas do fato de a composição etnolingüística da região de Luanda ser majoritariamente Ambundo. A ocupação portuguesa dessa regiāo foi a mais antiga e intensa no país, remontando ao período do tráfico de escravos (séculos XVI a XIX). A antigüidade da colonização, somada ao papel de proa que sempre assumiu na economia colonial e, depois, no país

6 As populações bakongo, de língua kikongo, somam cerca de um milhão de pessoas em Angola, atualmente. No período pré-colonial comportavam o Reino do Kongo, formado no século XIV, que no seu apogeu compreendia uma área que é hoje a parte do sul do Gabão, o sudoeste do Congo e do Zaire e o noroeste de Angola. Foi com o Reino do Kongo que os portugueses estabeleceram seus primeiros contatos na costa ocidental africana, em fins do século $\mathrm{XV}$, a princípio mantendo relações igualitárias de comércio e intercâmbio. Mais tarde, o comércio passou a ser eminentemente escravagista e, conseqüentemente, desestruturador das sociedades formadoras deste reino. independente, fez de Luanda uma região sui generis em Angola.

A "sociedade crioula" (que deu origem a um setor importante do que chamarei de "sociedade luandense") diz respeito a uma formação social antiga, produzida pelo período do tráfico de escravos em Angola. Nesse período, setores da sociedade local de Luanda e da região do rio Kwanza (sul de Luanda), além da cidade de Benguela, ao sul do país, foram responsáveis, em parceria (desigual) com portugueses e brasileiros, pela empresa do tráfico.

Isso proporcionou a emergência de uma pequena burguesia negra e mestiça angolana, que num amalgamento com o setor branco colonial produziu uma sociedade original, no sentido social e cultural. As marcas mais evidentes da crioulização dessa sociedade verificavam-se pela difusão do kimbundo como língua de uso doméstico e língua franca no comércio do interior, pela formação de famílias mistas, pela convivência inter-racial (que não supõe, obviamente, a ausência de conflito racial ou a inexistência de hierarquias de base racial). A adoção de usos e costumes africanos (que muitas vezes "escapavam" para a esfera pública), associada ao aprendizado do português e dos costumes metropolitanos, conferiu a essa população um forte sentido de enraizamento e de falta de identidade com o resto do território, majoritariamente rural e que, na época, ainda não tinha sido integrado completamente ao sistema colonial.

Essa sociedade crioula ruiu com a transição do sistema colonial do trato negreiro para a colonização "moderna" portuguesa, no início do século XX. A nova forma de colonização implicou a prevalência do poder metropolitano sobre a elite colonial, a intensa entrada de colonos portugueses, que ocuparam os espaços dos 
"filhos da terra". Neste processo, destaca-se o afastamento dos negros e mestiços dos cargos da administração e a conseqüente perda do seu relativo poder econômico.

Esse novo período do colonialismo português em Angola consolidou a centralidade de Luanda como pólo político e econômico da colônia. A alta taxa de urbanização e o aumento da presença portuguesa (com cada vez mais segregação entre africanos e metropolitanos) faz de Luanda uma cidade com forte influência lusitana.

A progressiva perda da matriz africana (ou pelo menos de seus elementos mais visíveis) por parte da população "assimilada" (não branca) e a falta de identidade com a população rural são características marcantes da sociedade luandense até o período posterior à independência. Cabe ressaltar também a forte influência urbana da capital sobre toda a região do interior kimbundo (áreas de Malange, Kwanza Sul), que fez expandir esse modo de vida de forte marca lusitana/crioula.

Por sua vez, as populações bakongo, situadas no norte/noroeste de Angola, foram encontrar, por diversos motivos, sua principal referência urbana em Leopoldville, capital do Congo Belga. Para esses grupos de mesma origem, descendentes das populaçôes que formavam o antigo reino do Kongo, a fronteira nunca foi uma barreira, e viagens constantes eram feitas entre as duas colônias.

No Congo Belga, a comunidade angolana podia contar com uma rede de relações provenientes do parentesco alargado, que incluía parentes nascidos do lado norte da fronteira, além dos que já tinham migrado anteriormente. Essas redes de relações possibilitaram uma inserção relativamente rápida no mercado de trabalho ou uma retaguarda que garantia a sobrevivência dos recém-chegados. As possibilidades de estudo, ainda que dentro do enquadramento restritivo colonial, eram muito maiores do que no norte de Angola, bem como as de aprendizagem profissional.

Esse trânsito transformou-se em exílio permanente, do lado norte da fronteira, com a tomada das terras dos angolanos pelos colonos brancos, a partir da década de 1940, e com o início da guerra anticolonial, a partir de 1961. O desenrolar da guerra fez a saída de angolanos aumentar drasticamente, conferindo a essas populaçôes o status de refugiadas. Os angolanos refugiados fixaram-se na região do Baixo Congo (área rural) e na capital, Leopoldville (depois Kinshasa, com a independência do Congo/Zaire, em 1960).

Essas populações ${ }^{7}$ tiveram praticamente $\mathrm{o}$ mesmo tipo de inserção das populações emigradas anteriormente para o Zaire: inserção através das famílias e, na cidade, no setor do comércio. Provavelmente, é a partir desse período (1961) que se verifica o crescimento do setor informal da economia na capital do Congo/Zaire.

\section{O RETORNO DO EXILIO E O SURGIMENTO DO GRUPO DOS “REGRESSADOS”}

Com a independência de Angola já se verificava o retorno de muitos angolanos ${ }^{8}$. O desejo de retorno dava-se tanto pelos laços familiares e de amizade deixados para trás quanto pela busca de uma "terra prometida"

7 A estimativa de entrada angolanos no Zaire entre 1961 e 1965 é de cerca de 400 mil pessoas.

8 O número de angolanos e seus filhos que retornaram para Angola é bastante impreciso, considerando que uma parte da população fixou-se nas províncias angolanas de origem - Zaire e Uíge. Estimo, arriscadamente, que, em Luanda, a população regressada seja da ordem de 300 mil. 
que, livre da opressão portuguesa, ofereceria melhores condições de vida, impossíveis de serem conquistadas no Zaire, que atravessava sérios problemas de ordem econômica.

O período de transição foi marcado pelos confrontos, na capital angolana, entre o MPLA e a FNLA. O confronto armado entre estes dois movimentos de libertação o terceiro movimento, a UNITA, havia se retirado de Luanda nesse período - marcou profundamente a sociedade luandense. As tropas da FNLA eram compostas por angolanos do norte de Angola, por exilados no Zaire e também por tropas do exército zairense, dado o apoio determinado do governo zairense de Mobutu Sesse Seko à FNLA.

Do ponto de vista dos habitantes de Luanda, os angolanos regressados do Zaire e estabelecidos na capital, durante e depois dos conflitos entre os dois movimentos, tivessem ou não relações diretas com a FNLA, adquiriram a alcunha de estrangeiros. No mesmo sentido, a entrada das tropas da FNLA foi identificada como uma invasão zairense e estrangeira. A identificação simplista e depreciativa regressados $=$ FNLA $=$ zairenses se tornou o raciocínio padrão para setores da população de Luanda.

O aprendizado do modo de vida urbano de Kinshasa, comparado com o luandense, diferenciava os regressados em diversos aspectos: no vestuário, na alimentação, no tipo de habitação, nas práticas religiosas e em outros hábitos e costumes. Esse modo de vida era percebido pelos regressados como "uma cultura mais africana" em oposição à dos luandenses, considerados mais voltados para Portugal e para o Brasil.

Os regressados passaram a ocupar principalmente certos bairros da periferia de Luanda, mas não se restringiram a um gueto, morando também nos bairros do centro da cidade. Depreende-se disso uma grande diversificação entre os regressados quanto ao nível econômico, à escolaridade, à capacitação profissional, etc.

Quer pelo desenvolvimento do comércio informal, numa economia controlada pelo Estado, quer pela entrada de quadros qualificados no setor do funcionalismo público, os regressados demonstraram uma enorme capacidade de adaptação e transformação de suas condições de vida num meio relativamente hostil. Essa hostilidade, que inicialmente devia-se à identificação dos regressados com participantes da FNLA - partido inimigo da maioria dos habitantes de Luanda - foi depois sendo demarcada pela rejeição à introdução de elementos culturais e costumes percebidos como estranhos à população local.

Delineou-se então um acirramento das diferenças entre "regressados" (que formavam um grupo francamente minoritário) e "luandenses", expressas por certos símbolos e valores. A introdução de modos de vida aprendidos no Zaire acarretou aos regressados o estigma, conferido pelos luandenses, de "estrangeiros" e "zairenses".

A língua portuguesa, amplamente utilizada em Luanda ao longo do período colonial, e usada após a independência como língua de unidade nacional, língua de cultura $^{9}$ e de Estado, jamais havia sido considerada uma língua nacional exclusiva, no sentido de que se pudesse definir quem

9 A expressão "língua de cultura" é utilizada aqui para denotar apenas a preferência (não a exclusividade) de uma língua para fins de expressão artística, sobretudo literária, científica e de comunicação social e não indica um sentido valorativo ou hierarquizante de minha parte. 
era ou não angolano a partir da competência do seu uso. Em Luanda, a partir da entrada dos regressados, que tinham como língua principal não o kikongo (língua materna Bakongo) mas o lingala (língua veicular de Kinshasa), o português passou a ser usado, pelos luandenses, como um demarcador de nacionalidade e de "angolanidade".

Em resposta a essa postura, os regressados, na busca de situarem-se como pertencente à mesma "nação", passaram a considerar a cultura bakongo/regressada como sendo a cultura verdadeiramente "africana", em oposição à luandense, "crioulizada", "destribalizada".

No contexto político angolano, a noção de "crioulo" foi assumindo um perfil sócioeconômico e racial, identificando-se, no discurso dos setores de oposição, a um grupo de "mulatos" que ocupa os mais altos escalóes do poder e do funcionalismo público. O caráter de "destribalizado", longe de ser um fator de afirmação de nacionalidade, foi encarado pelos regressados como uma africanidade insuficiente, ou seja, faltaria aos luandenses o ingrediente, a categoria obrigatória da africanidade, que seria o pertencimento étnico (Pereira, 1997).

Chamo atenção, contudo, para o fato de o confronto político-cultural entre "luandenses" e "regressados" estar formatado pelo confronto de dois tipos de vida urbana: a de Luanda e a de Kinshasa. A reivindicação de maior "africanidade" feita pelos regressados Bakongo não se dá num apelo à uma africanidade rural (tal como faz Savimbi, líder da UNITA, por exemplo). Tanto a "africanidade" bakongo/zairense/ regressado, como o orgulho "nacional/moderno" propagado pelos luandenses se faz num quadro de vivência urbana de pelo menos mais de duas décadas para os dois grupos e diz respeito a modos de vida bastante diferenciados experimentados nas duas capitais.

A concentração dos regressados em certos bairros da periferia da capital angolana e a criação de organizações internas (igrejas, associações de ajuda mútua, organizações não governamentais, além de uma profusão de negócios, casas comerciais, oficinas) consolidaram a visão dos regressados como um grupo coeso, solidário, assumindo uma identidade e uma auto-organização próprias, distintas do resto da sociedade luandense.

Com o passar do tempo, e considerando as mudanças políticas, econômicas e sociais ocorridas em Angola, especialmente em Luanda, pode-se perceber a transformação das relações entre os dois grupos. Dois aspectos dessa transformação foram a abrupta transição para a economia de mercado (fins da década de 1980) e as eleiçôes (1992), com a posterior retomada da guerra civil. Verificam-se então os aspectos de integração e contato, bem como os fatores de etnicidade, de estigma e da violência atuando na separação dos grupos identificados.

A Sexta-feira Sangrenta foi uma das conseqüências do agravamento da tensão que sucedeu à não aceitação, por parte da UNITA, dos resultados das primeiras eleições em Angola, ocorridas em fins de setembro de 1992. Os combates se reiniciaram, de forma irrevogável, no começo do ano de 1993.

Os regressados, na cidade de Luanda, tinham votado maciçamente em Jonas Savimbi, a despeito da existência de todos os partidos políticos de origem bakongo que se formaram após a adoção do multipartidarismo. Talvez porque vissem em Savimbi a única opção capaz de se contrapor ao governo, cuja imagem estava, na época, 
extremamente desgastada. O fato é que, desde dezembro de 1992, já havia registros de ataques, assaltos e intimidaçôes nos bairros regressados, feitos por parte de policiais, milícias, militares ou bandidos fardados (atendendo às exigências do processo de paz, o governo havia desmobilizado um grande contingente de militares).

Na manhã do dia 22 de janeiro de 1993, motivados por boatos sobre a infiltração de soldados zairenses no norte de Angola em apoio à UNITA, explodiram ataques aos moradores de Luanda que pudessem ser identificados como zairenses ou regressados. A identidade das pessoas era demarcada pelo modo de vestir, de falar e especialmente pela forma como elas pronunciassem a palavra "arroz" (o modo de pronunciar afrancesado ou lingalizado - é facilmente identificável na pronúncia dos dois "rr"). As informações sobre o número de mortos e feridos ainda hoje são contraditórias e desencontradas. Os debates levados a cabo no Parlamento, bem como os inquéritos policiais foram inconclusos quanto aos responsáveis pelas agressões.

Desde então, nunca mais foram registrados ataques semelhantes à "Sexta-feira Sangrenta" considerada por diversos analistas como um evento atípico num contexto de tensão étnica que, até então, nunca havia ultrapassado as discriminaçôes e agressões verbais. Nesta altura, verificou-se uma reação importante de elites bakongo/regressadas a partir da circulação de panfletos e da realização de mobilizações nos bairros de predominância regressada com acusações ao governo pela responsabilidade dos ataques. Notava-se nos discursos das elites bakongo um forte apelo étnico, por vezes separatista, recorrendo à unidade Bakongo através da referência ao passado glorioso do reino do Kongo, marcando sua diferenciação e especificidade em relação ao resto do país e, sobretudo, às elites de Luanda ${ }^{10}$.

Do ponto de vista da integração, com o tempo, o contato/convívio/conflito entre luandenses e regressados se rotinizou. Podem ser identificados alguns elementos externos que acompanharam essas transformações.

Os acordos de Lusaka, em 1994, diminuíram o impacto da guerra, ainda que não tenham cessado por completo os conflitos (que foram retomados em fins de 1998). Houve continuidade dos trabalhos da Assembléia Nacional e a criação do Governo de Reconciliação e Unidade Nacional (GURN), que vinha tentando conferir uma normalidade institucional a um lento processo de paz, que veio a demonstrar-se ineficiente.

Por outro lado, houve mudança no contexto regional. A deposição e posterior morte de Mobutu Sesse Seko e o apoio do governo angolano ao novo presidente do Zaire, agora renomeado Congo, Desiré Kabila, pôs fim a uma rivalidade de mais de trinta anos entre Angola e o Congo.

A abertura da economia, e sua desarticulação, acarretou um descomunal crescimento e generalização do mercado informal, com a entrada de diversos segmentos da população neste setor, antes de presença predominante dos regressados. $\mathrm{O}$ estigma de comerciantes ilegais, "candongeiros", conferido aos regressados foi aos poucos perdendo força perante a necessidade de diversificação de atividades econômicas que atingiu toda a população. Permanece ainda a acusação de que os regressados "introduziram" o comércio ilegal, além da corrupção, na economia da capital.

10 Uma análise mais detida sobre o evento da Sexta-feira Sangrenta, a reação da elites bakongo/ regressadas, é desenvolvida na minha dissertação de mestrado (Pereira, 2000, capítulo 4).

cadernos de campo : n. $10 \cdot 2002$ 
Internamente, com o tempo de vivência em Luanda, muitas mudanças aconteceram no seio da população regressada. O progressivo domínio do português pela maior parte desse grupo, especialmente a população mais jovem, foi um fator importante de integração e diminuição do estigma. A forte solidariedade de grupo e o relativo sucesso de vários indivíduos entre a comunidade regressada (desde jogadores de futebol a professores universitários e empresários) impuseram um certo respeito e reconhecimento por parte da sociedade circundante. É notável que a diversidade interna dessa população não diminuiu sua autorepresentação como portadora de uma identidade comum, centrada na identidade Bakongo.

\section{A LÍNGUA}

A diferença cultural mais sentida e expressa por regressados e não regressados está nas línguas - lingala e português - e no peso e sentidos diferenciados que cada grupo dá ao uso de uma e outra. No caso, trata-se de uma língua herdada do colonizador e de uma língua não angolana, mas veicular da região da capital do Congo/Zaire. Essas diferenças dizem respeito à experiência de cada grupo em meios urbanos bem distintos - Luanda e Kinshasa - e a inserções coloniais também distintas - Angola e Zaire.

No caso dos luandenses, o uso do português remonta ao período do tráfico. O longo contato com os portugueses, a criação de uma sociedade crioula e sua rede para o interior fizeram do português uma língua muito disseminada e, mais que isso, uma língua bastante transformada por seu contato longo e estreito com o
Kimbundo (que tinha também um lugar fundamental como outra língua veicular desse período, que vai até o século XIX).

A apropriação da língua portuguesa como língua nacional e de contestação nacionalista ${ }^{11}$ segue um longo processo na formação literária angolana, que inicia-se na imprensa nativista de fins do século XIX e vai até o moderno romance angolano de meados do século XX. Contudo, a expansão do português se deu, obviamente, dentro do projeto colonial de "portugalização" - uma palavra de ordem mais significativa que "civilização" - levado a cabo por meio da Igreja Católica.

Durante a luta anti-colonial o português foi a melhor forma dos nacionalistas de diversas partes do país se comunicarem. Assim, a idéia de "Angola" ganha sentido em grande parte devido à noção de uma língua partilhada, através de uma experiência colonial comum e de uma luta unificadora (Serrano, 1988).

De acordo com contingências pragmáticas ou obedecendo a propósitos e a projetos colonial ou pós-colonial, o fato é que as línguas maternas angolanas sofreram uma grande marginalização. No tempo colonial, o objetivo de "portugalizar" impedia a utilização das línguas africanas no ensino básico. O Estado português privilegiava a Igreja Católica para a ação

11 O uso da língua do colonizador como arma para a luta pela independência foi comum em praticamente todos os países africanos, sobretudo pela luta ter sido promovida pelas elites educadas à ocidental, que precisavam obter reconhecimento político junto à comunidade internacional. $\mathrm{O}$ valor e os sentidos da internalização da língua do colonizador na cultura do colonizado são alvo de intensas discussões, políticas, acadêmicas, ideológicas que ganharam muito espaço no âmbito dos chamados estudos "pós-coloniais" (Appiah, 1997). Defendo aqui que embora não separado deste contexto, o caso angolano possui especificidades importantes. Busco destacar, sobretudo, os aspectos que ressaltam a disseminação e o enraizamento do português na sociedade angolana e não só nas suas elites. 
missionária, marginalizando as Igrejas protestantes (quase todas estrangeiras, o que ameaçava o projeto portugalizador), que tinham como método e doutrina o ensino nas línguas locais.

No período da independência, o problema das línguas torna-se ainda mais complexo. Do ponto de vista pragmático, a intenção do Estado revolucionário de alfabetizar em massa, em nível nacional e de forma centralizada, acarretou a alfabetização exclusiva em língua portuguesa, já que esta possibilitaria a consecução da unidade nacional.

O reconhecimento da importância das línguas nacionais como expressão das culturas angolanas, no sentido de estimular efetivamente o seu uso e criar meios de consolidá-las, esbarrou não somente na falta evidente de recursos, mas também numa certa incompreensão em torno do que é, ou deveria ser, a valorização da "cultura angolana". A tendência de perceber a cultura e suas manifestaçôes como elementos folclóricos, o distanciamento entre os centros de poder e as realidades rurais (em Angola, as línguas africanas são faladas sobretudo na área rural, as cidades são bastante lusófonas) e um certo receio de que a valorização dos grupos étnicos fosse associada ao "tribalismo" (gravíssima acusação nos primeiros anos após a independência) foram fatores ideológicos e culturais que relegaram as línguas angolanas à marginalização.

Por sua vez, no Congo Belga, a alfabetização e o ciclo básico eram ensinados nas línguas locais, com uma transição para o francês no ensino intermediário. $\mathrm{O}$ ensino também estava nas mãos dos missionários, sobretudo católicos. Mas não havia, como no caso $\mathrm{da}$ colônia portuguesa, um desenraizamento tão profundo, interditando ao "indígena" o aprendizado na sua língua materna.

O processo nacionalista no Congo Belga radicalizou-se de modo fortemente racializado e encontrou uma de suas conseqüências no movimento da autenticité, implantado por Mobutu Sesse Seko em fins da década de 1960. Este movimento cultural tinha, na sua origem e em suas formulações iniciais, objetivos bem diversos do que foi propagado pelo ditador e que não estão no alcance deste artigo. Todavia, apontamos neste movimento a exortação aos "valores culturais africanos" e a imposição aos cidadãos zairenses de trocarem seus nomes de origem européia por nomes "africanos". Este foi, certamente, um movimento que teve impacto sobretudo no meio urbano.

A questão da troca de nomes teve outras implicaçõos para os angolanos exilados no Zaire, mas o que cabe destacar aqui é o caráter de rejeição ao legado colonial no seu sentido cultural. Assim, ainda que o francês seja a língua dos intelectuais, $\mathrm{da}$ universidade, do liceu, etc., para um congolês pode parecer estranho assumir uma língua colonial como vernáculo e, mais que isso, como uma língua da cultura nacional. Não faz sentido para o congolês/zairense ou regressado que um angolano não saiba falar outra língua que não o português. $O$ fato de a língua portuguesa ser considerada como um fator de "angolanidade", de identidade nacional, caracteriza, para um congolês, um aspecto de subserviência e, para o angolano (nesse caso, o luandense, já que estamos nos referindo todo o tempo à relação regressadoluandense), uma apropriação legítima de um legado cultural enraizado por séculos.

A língua portuguesa em Luanda foi sendo progressivamente utilizada pela sociedade circundante para marcar sua 
diferença frente ao grupo imigrado e para classificá-lo como estrangeiro. Nesse contexto, ela se cristaliza na capital como a língua da identidade nacional por excelência.

\section{O LUGAR DO KIKONGO}

A inserção do grupo regressado na sociedade luandense implicou o aprendizado progressivo da língua portuguesa, pela necessidade de inserção no mercado de trabalho, pela convivência no ambiente escolar ou mesmo como uma estratégia para dominar os diversos códigos e símbolos que definem para a sociedade circundante o pertencimento à nacionalidade angolana. Por outro lado, a distintividade dos regressados como um grupo separado se traduzia pela manutenção do uso do lingala como língua interna ao grupo, não como uma língua de "gueto", mas uma língua que se ouvia cada vez mais nos mercados, nas ruas e em outros ambientes de concentração de regressados.

Nesse "embate" entre o lingala e o português, perdeu o espaço o kikongo, que seria a língua de expressão original do povo bakongo. O kikongo, portanto, é muito pouco falado entre os Bakongo/regressados ou, pelo menos, tem pouquíssima expressão pública em Luanda. A perda de espaço do kikongo vem acontecendo desde a migração de angolanos para o Zaire, sobretudo Kinshasa, onde o lingala é a língua veicular por excelência.

A proeminência do lingala na região da capital zairense é explicada por Gondola (1996) como obra deliberada da dominação colonial e não como um processo de dominação de um grupo sobre outros. $\mathrm{O}$ lingala teria sido a língua obrigatória do ensino técnico na região da capital. Sendo uma língua de muito fácil assimilação, com capacidade de absorver vocábulos de origens diversas, sobretudo do francês, o lingala foi se impondo em toda a região que orbitava em torno da capital congolesa, inclusive no Congo Francês. Após a independência, o lingala manteve-se como uma língua importante no Estado zairense, sobretudo por ser a língua do exército de um governo militarizado. Há, sobretudo, o aspecto da influência cultural do lingala pela grande aceitação e disseminação da música zairense dentro e fora de África.

A população angolana emigrada ou exilada no Zaire incorporou rapidamente o lingala. O kikongo era considerado, na capital zairense, uma língua de rurais, sendo seu uso bastante restringido no âmbito público.

$\mathrm{O}$ retorno à Angola e a inserção em Luanda tornaram o kikongo uma língua pouco utilizável, à medida que o aprendizado do português tornou-se prioridade nas estratégias das famílias regressadas e que as gerações mais jovens, sobretudo as que nasceram em Kinshasa, tinham pouco, senão nenhum, domínio da língua materna ${ }^{12}$.

O kikongo tem sido uma língua restrita aos mais velhos. É também a língua do meio religioso e das cerimônias de noivado, casamento, óbito. Ela pode ser usada no âmbito doméstico, nas resoluções das questôes familiares em que se recorre às autoridades do grupo, quando há apelo ao saber tradicional.

Ultimamente, percebe-se que o kikongo tem sido valorizado por uma parte das elites

12 As famílias ou indivíduos que, no retorno a Angola, passaram algum tempo na aldeia de origem puderam retomar o contato com o kikongo, que é muito forte na área rural. Aqueles que foram diretamente de Kinshasa para Luanda, ou tiveram uma curta passagem pela área de origem, provavelmente dominam muito pouco a língua dos pais. 
bakongo. No contexto do embate ideológico com a sociedade luandense - em que esta é acusada de não dominar qualquer língua materna e ter-se "destribalizado" - o conhecimento e a exibição do conhecimento do kikongo por parte da elite bakongo é utilizada como um diferencial importante. Nesses meios, há uma preocupação com o ensino do kikongo aos mais jovens. Essa preocupação também é seguida de perto pelas igrejas de maior acolhida entre bakongos e regressados.

É muito cedo para dizer se o kikongo se afirmará no meio urbano entre os jovens que têm no lingala uma língua de mais largo alcance, que lhes permite transitar por diversos países e regiōes. Por outro lado, o uso disseminado do português entre os jovens regressados indica uma grande capacidade de adaptação e integração. Percebe-se também um maior interesse dos mais jovens em dominar outras línguas, tais como o inglês e o francês, que podem lhes permitir uma maior mobilidade.

A tabela que se segue é uma tentativa de ilustrar, de maneira bem ampla, ainda que talvez um pouco estanque, os contextos mais comuns do uso do lingala, do português e do kikongo. Não é fruto ainda de uma pesquisa empírica bem sedimentada, mas penso que pode auxiliar o entendimento da complexidade lingüística de Luanda, sobretudo do ponto de vista dos bakongo e regressados.

Lembro que em Luanda convivem outros grupos étnicos que trazem as línguas de suas regióes para a capital. Avalio, contudo, que o português é incontestavelmente a língua hegemônica da capital, seguida pelo lingala e pelo kimbundo, este mais entrecortado e misturado com o português do que usado como uma língua corrente.
Espaços do uso Lingala, do Kikongo e do Português na perspectiva do regressado

\begin{tabular}{|c|c|c|}
\hline KIKONGO & LINGALA & PORTUGUÊS \\
\hline $\begin{array}{c}\text { Aldeia (região de } \\
\text { origem) }\end{array}$ & $\begin{array}{l}\text { Bairros regressados } \\
\text { /bakongo }\end{array}$ & Cidade em geral \\
\hline Âmbito Doméstico & $\begin{array}{c}\text { Rua entre } \\
\text { regressados/bakongo }\end{array}$ & $\begin{array}{c}\text { Rua com } \\
\text { desconhecidos }\end{array}$ \\
\hline $\begin{array}{c}\text { Cerimônias e rituais } \\
\text { religiosos (noivado, } \\
\text { casamento, óbito). } \\
\text { lgrejas nos bairros } \\
\text { regressados/bakon- } \\
\text { go } \\
\end{array}$ & $\begin{array}{l}\text { Igrejas nos bairros } \\
\text { regressados/bakongo }\end{array}$ & Igrejas em geral \\
\hline $\begin{array}{l}\text { Resolução de } \\
\text { problemas em } \\
\text { família }\end{array}$ & $\begin{array}{l}\text { Entre regressados, } \\
\text { parentes e amigos }\end{array}$ & $\begin{array}{l}\text { Ambientes de trabalho } \\
\text { escolar; órgãos } \\
\text { públicos }\end{array}$ \\
\hline $\begin{array}{l}\text { Mercado (mulheres } \\
\text { mais velhas) }\end{array}$ & Mercado & Mercado \\
\hline & Candongueiro & Candongueiro \\
\hline Mais velhos & Adultos e jovens & $\begin{array}{l}\text { Adultos, jovens e } \\
\text { crianças }\end{array}$ \\
\hline
\end{tabular}

A partir desta tabela arriscamo-nos a fazer mais algumas considerações. Percebe-se que o domínio do português é fundamental para garantir o trânsito do regressado por todos os circuitos da vida da cidade - ambiente de trabalho, escolas, universidades, ruas, a cidade em geral (considerando principalmente o centro da cidade). $O$ lingala tem seu espaço mais restringido, mas é presente em alguns meios de circulação notória dos regressados, como o transporte (candongueiro) e o mercado. O kikongo é ouvido apenas no âmbito doméstico e familiar, sobretudo no contexto religioso ou em situações "tradicionais".

Podemos considerar, a partir de Raffestin (1993), que se baseia no lingüista Henri Gobard, um modelo de análise que contém 
quatro tipos de linguagem, em uma dada área cultural: a linguagem vernácula, local ou cotidiana, que o autor chama de linguagem de "comunhão" e que tem um caráter espontâneo; a linguagem veicular, com a função de comunicação, de âmbito nacional ou regional; a linguagem referencial ou de cultura, na qual o grupo expressa e dá continuidade a seu legado histórico e cultural e a linguagem mítica, que se relaciona ao passado imemorial e ao sagrado.

Sendo possível a um dado grupo utilizar uma língua para cada "função", é também plausível que apenas uma língua assuma as quatro funções ${ }^{13}$. No caso dos regressados, é perceptível que o lingala tem exercido a função do vernáculo, cabendo ao português, cada vez mais, a dimensão veicular. $\mathrm{O}$ kikongo vem tendo, por vezes, o papel referencial (disputando este espaço com o francês no caso dos bakongo mais educados). Cabe ao kikongo, sobretudo, a dimensão mítica.

Nos momentos agudos de disputa política, em que a etnicidade ganha espaço nos discursos, como no caso da Sexta-feira Sangrenta, o kikongo sai do plano mítico ou da esfera meramente privada e assume outros significados, como pode ser visto nos panfletos e nas manifestações de grupos políticos bakongo em que são feitas referências nesta língua. A língua materna permanece, assim, na maior parte das vezes, como uma reserva simbólica indicando o espaço - privado - da família, da religião e da autoridade dos mais velhos.

O português, para a população luandense, assumiu as funções tanto de

13 O autor cita o caso da língua inglesa que, para os norteamericanos, assume as quatro funções. Pode ser o caso da língua portuguesa para a maioria dos brasileiros, considerando a incorporação nesta língua de elementos das línguas africanas e indígenas. vernáculo (língua de grupo, de comunhão) como de língua veicular, na medida em que foi a língua de comunicação, da economia e do Estado. É sobretudo a língua referencial, língua de cultura e de identidade, na qual a literatura angolana vem se expressando, de forma particular, pois "kimbundizada", o que indica sua apropriação, transformação e enraizamento.

O português não é apenas a língua dos luandenses, da capital. À expansão do português durante o período colonial seguiu-se sua utilização como forma de os nacionalistas se comunicarem para combater o regime. A propagação da guerra civil, que é uma das formas de penetração do Estado angolano (já que este recruta soldados para o exército por todo o território), foi também um importantíssimo vetor da língua portuguesa. Angola é um país sui generis em África, posto que possivelmente a maior parte de sua população expressa-se na antiga língua do colono, fenômeno incomum no continente. Isso descaracteriza o português como uma língua apenas urbana, da capital e das elites, e torna complexo o quadro lingüístico angolano.

É preciso ainda qualificar o que significa "expressar-se" em português. Provavelmente, quase a metade das pessoas que falam português o tem como única ou primeira língua de expressão, e é este dado que remete o português à sua dimensão referencial, e não apenas de vernáculo ou veicular, para uma parte significativa da população.

A língua é um instrumento de produção e manifestação de poder. Expressa modos de vida, de ser e estar, de classificar e ordenar a realidade. A marginalização de uma língua caracteriza também a marginalização do grupo que a porta. Nesse sentido, a apropriação da língua portuguesa como língua do Estado e sua generalização como 
língua veicular, mais do que mera "língua oficial”, relega para as esferas não públicas da vida social outras línguas concorrentes.

O não domínio do português por setores da população impede o acesso dessas à plenitude da vida social, que engloba as dimensões pública e privada. No caso do grupo regressado, as pessoas com maior dificuldade em falar português são as mulheres mais velhas, mas não só. Essas pessoas acabam por permanecer nos bairros e têm restringido o acesso ao mercado de trabalho. Ainda que os mercados livres não ofereçam dificuldades aos falantes do lingala, o campo de atuação torna-se limitado. Não é possível ao mau falante de português estabelecer outras relações com pessoas que não sejam de seu meio étnico. Acima de tudo, esses indivíduos se tornam mais vulneráveis à arbitrariedade dos poderes.

A permanência do uso do lingala que, no caso dos regressados, concorre com o português no domínio do vernáculo (expresso pelo uso do lingala nas ruas, nos mercados) indica a manifestação de um modo de vida que insiste em estar no espaço público, ainda que este seja dominado pelo português.

Todavia, o sotaque dos regressados que falam português os identifica frente aos luandenses e indica uma "falta", um domínio insuficiente da língua, que lhes retira um capital importante para o pertencimento e o controle dos espaços da cidade e nacional. Não é que os regressados não possam se comunicar em português e serem entendidos (dimensão veicular do português em Angola), trata-se de um domínio da língua portuguesa que indica o pertencimento a ela e a uma comunidade de sentido - posta pela dimensão do vernáculo (Anderson, 1989). Esse domínio distingue os regressados dos luandenses e dá aos últimos a primazia daquela "angolanidade" a que nos referimos neste artigo: uma identidade nacional hegemônica que, ao menos em Luanda, tem passado pelo critério da "expressão" em língua portuguesa.

Essa discussão em torno das línguas e do seus diversos usos é extensa e tem diversos desdobramentos. Cabe aqui apenas reforçar que esse é um ponto nodal da discussão que envolve a "questão nacional", suas formas de expressão, seus critérios de pertencimento e exclusão.

É interessante perceber o sentido da palavra "expressão", que se contrapõe à noção de "língua oficial" ou ao termo mais neutro "de fala portuguesa ou francesa". A menção aos países de língua oficial portuguesa como "países de expressão portuguesa" indica uma partilha cultural, uma dimensão afetiva, que é o que justamente tem sido o português para muitos angolanos, mas não para todos, ou pelo menos não exclusivamente. Ainda que ninguém em Angola defenda o uso exclusivo da língua portuguesa e muitos sejam defensores ardorosos do multilingüismo, na prática tem sido difícil dissociar a construção de uma identidade nacional angolana fora da "expressão", no sentido mais afetivo possível, em língua portuguesa.

\section{MOBILIDADE E TERRITÓRIO}

$\mathrm{O}$ apelo a identidades mais amplas, como "africana" e "bantu", tem sua maior referência no fato de o grupo Bakongo ser uma etnia cortada por fronteiras nacionais e por sua grande mobilidade territorial, através da articulação de redes comerciais, e circulação por diversos países africanos.

A valorização da mobilidade regressada expressa-se no fato de os Bakongo/regressados se referirem aos luandenses com o termo 
"fixados" ou a expressão "aqueles que nunca saíram de Angola". De fato, constata-se que os luandenses viajam bastante, mas os destinos preferidos dos angolanos da capital são invariavelmente países europeus, sobretudo Portugal, e Brasil. Só muito recentemente as famílias luandenses têm aberto seu leque de opçóes migratórias - seja para compras, estudos ou para fixar residência - em países africanos, como a África do Sul.

Pode-se perceber, através das categorias veiculadas por regressados/bakongo que, por trás dessa forma específica de mobilidade existe uma concepção de território $^{14}$ decorrente.

Um grupo originário de uma etnia atravessada por várias fronteiras e que se constituiu pela mobilidade, pela migração, pelo exílio e pelo comércio de grande distância constrói, organiza e estabelece relações no espaço de forma diferenciada. A população de Luanda, por sua vez, estabelece no seu espaço - e note-se, o espaço da capital do país - outras relações com outros espaços, como Portugal e Brasil.

A história da cidade de Luanda se constituiu através de uma intensa relação comercial com o Brasil e de uma relação política de submissão a Portugal, na qual ela era o centro da colônia. Luanda permaneceu "atlântica" após a

14 Entendo "território" como uma produção social do e sobre o espaço (Raffestin, 1993). O território pode ser produto de relações sociais efetivamente realizadas ou ser um projeto, uma representação, um ideal. A "produção social sobre o espaço" supõe relações de poder entre atores sociais, grupos, classes e o Estado, envolvendo diferentes potenciais e representações diversas do espaço (este seria a matéria-prima sobre a qual se cria e produz o território). Estas representações são de alguma forma partilhadas e/ou estão em concorrência. O território, para um grupo social, pode até mesmo incluir vários territórios descontínuos (no tempo e no espaço). independência, tanto do ponto de vista político - envolvimento com a Guerra Fria, política externa pouco centrada em África (Pereira, 1999) - como do cultural - grande influência brasileira e portuguesa.

Existe assim um grupo, o regressado/ bakongo, que tem como referência um território localizado regionalmente (território contínuo), atravessado por fronteiras. As relações (familiares, comerciais, culturais) que se espalham por este território não são facilmente afetadas quando há o estabelecimento de fronteiras nacionais/estatais.

Por outro lado, os grupos que têm Luanda como centro constróem suas referências - culturais, políticas etc. - num território descontínuo (Angola, Portugal, Brasil), sendo, portanto, mais fácil estabelecer ou perceber rupturas. Portugal é a antiga metrópole. O Brasil, embora possa ser um espelho para Angola e tenha em relação a ela algumas convergências culturais, não é África, está localizado do outro lado do oceano e possui uma história muito diferenciada. É mais fácil traçar cortes nesta relação do que num território contínuo que partilha histórias mais próximas e povos comuns, ou seja, relaçôes menos intangíveis.

O Reino do Kongo configura um território descontínuo no tempo - posto que não tem existência atual - e no espaço - pois corresponde a uma área cortada por várias fronteiras nacionais. Mas, do ponto de vista mítico, este espaço fragmentado pode ser reagrupado e reatualizado como um lugar de reafirmação de identidade, através dos discursos das elites bakongo/regressadas, como ocorreu após a crise deflagrada em torno da Sexta-feira Sangrenta. 
ETNIA DE FRONTEIRA E QUESTÃO NACIONAL

O estudo sobre os regressados de Luanda, suas organizações internas, seu posicionamento frente à sociedade hegemônica e as respostas que procuraram criar em busca de sua autoafirmação como grupo, às vezes distinto e separado (criação e afirmação de identidade étnica), às vezes integrado e pertencente ao todo nacional (afirmação de pertencimento nacional), é interessante para pensar sobre as alterações dos discursos e das disputas em torno da identidade nacional.

A dinâmica regressado $x$ luandense, contudo, está longe de ser a principal contradição identitária da sociedade angolana, que ainda permanece presa à bipolarização entre as duas maiores forças político-militares do país, o governo, comandado pelo MPLA, e o partido armado da UNITA, expressa na continuada guerra civil. Essas duas forças vêm representando duas formas de perceber o todo nacional a partir de perspectivas distintas que parecem se mostrar inconciliáveis.

Prevaleceu, a partir do governo do MPLA, uma perspectiva não racial, não étnica e não tribal, voltada para a construção de uma ideologia nacional de molde modernizador, bem ao caráter de sua elite, longamente urbanizada e ocidentalizada. A perspectiva "voluntarista" dessa elite teve como contrapartida uma visão homogeneizadora da sociedade angolana e um profundo desconhecimento das suas populações rurais, seus valores e aspirações. Esse desconhecimento deveu-se ao afastamento histórico da sociedade luandense das áreas do interior, o que acabou gerando uma profunda não identificação entre o meio urbano e a "África profunda", considerada, ainda que implicitamente, como um meio atrasado e "tribal"15.

É em nome da chamada "África profunda" que a UNITA de Savimbi apresenta sua oposição ao MPLA. Em seu discurso, diz atuar em nome das sociedades rurais, que são, para os dirigentes da UNITA (por sinal, também urbanizados e formados à ocidental), a verdadeira Angola genuína, autêntica ou realmente africana. Savimbi buscou apoiar-se na região do planalto central de Angola, região ovimbundo, cuja população teria sido a mais prejudicada desde a ocupação mais intensa dos portugueses em Angola, a partir da década de 1920.

É entre essas duas concepções (referidas aqui de forma um pouco grosseira) que prevalece a disputa que divide Angola até hoje, no sentido ideológico e cultural das concepções de nação e angolanidade. Porém, permanecem fora dessa contenda outras formas de perceber e conceber a nação e o nacional angolano. A especial inserção dos Bakongo na sociedade angolana, considerando a sua dimensão internacional e a história das suas elites, formadas no Congo, trazem outras perspectivas para esse debate.

Chamo atenção para a especificidade dessa argumentação "regressada", que traz para o debate a dimensão regional na qual Angola está inserida. É preciso lembrar que em Angola, dos três principais grupos etnolingüísticos, Ambundo, Ovimbundo e Bakongo, os dois primeiros estão inscritos no território

15 A organização do nacionalismo angolano no exílio e as dificuldades da implantação da guerrilha no meio rural mais densamente povoado também são fatores que explicam a pouca aproximação desses dois "mundos" angolanos. 
angolano $^{16}$. O grupo Bakongo encontravase cortado por fronteiras coloniais ${ }^{17}$, hoje nacionais. É com os recursos e o "capital" de uma "etnia de fronteira" que este grupo com um histórico de especificidade transnacional traz a reivindicação de uma identidade regional ou africana, pois não vêm encontrando no Estado nacional vigente um espaço político-institucional capaz de abrigar, dentro do todo nacional, todas as demandas que essa especificidade acarreta.

Houve uma evidente diminuição da imposição homogeneizante por parte do governo e retira-se, aos poucos, o véu que caía sobre as discussōes em torno das questôes sobre etnia e raça, antes temas tabus. As afirmaçōes em torno da real diversidade das sociedades que compõem o todo nacional não são mais percebidas atualmente como afirmaçōes seccionistas ameaçadoras da unidade do país.

Outras identidades vêm surgindo no espaço público, algumas que ultrapassam o âmbito nacional (identidades bantu, regionais, africana) e outras que, por vezes, lhe estão inscritas, mas que atravessam constantemente a fixidez de base territorial do Estado-nação (etnia, clãs, famílias, regiōes). A emergência de identidades nãonacionais - e transnacionais - vêm alterando e influindo decisivamente no conteúdo e na conformação de identidades nacionais em disputa. Torna-se um desafio político legítimo abrigar institucionalmente essas demandas, considerando que a diversidade étnica (e outras diversidades)

16 Além do pequeno grupo Nyaneka-Humbe.

17 Tal como todas os outros grupos étnicos angolanos de menor porte, como Lunda-Tchokwe, Nganguela, Herero Ovambo. não deve ser percebida, a princípio, como um fator de instabilidade.

\section{BibLIOGRAFIA}

ANDERSON, Benedict. Nação e Consciência Nacional. São Paulo: Editora Ática, 1989.

APPIAH, K. A. Na casa de meu pai: a África na filosofia da cultura. Rio de Janeiro: Contraponto, 1996.

GONDOLA, Charles Didier. Villes Mirrois: migrations et identités urbaines à Kinshasa et Brazzaville, 1930-1970. Paris: L'Harmattan, 1996.

MABEKO TALI, Jean-Michel. La "chasse aux Zairois" à Luanda. In: Politique Africaine:. L'Angola dans la guerre. Paris: no 57, março 1995.

PEREIRA, José Maria Nunes. Angola: identidade nacional e africanidade. Rio de Janeiro: Universidade Cândido Mendes, 1997 (mimeo).

PEREIRA, Luena Nascimento Nunes. Os regressados na cidade de Luanda: um estudo sobre identidade étnica e nacional em Angola. Dissertação de Mestrado. PPGAS/USP, 2000.

RAFFESTIN, Claude. Por uma geografia do poder. São Paulo: Editora Ática, 1993.

SERRANO, Carlos. Angola: nasce uma nação. Tese de doutoramento. PPGAS/ USP, 1988. 
cadernos de campo $\cdot$ n. $10 \cdot 2002$ 